\title{
Pensamento algoritmico, parametrização e urbanismo sustentável: uma avaliação de parâmetros para estratégias de projeto urbano inteligente
} Algorithmic thinking. parameterization and sustainable urbanism: an assessment of parameters for intelligent urban design strategies

\author{
> Fernando Lima \\ Universidade Federal de Juiz de Fora, Brasil \\ fernando.tadeu@uff.edu.br
}

\author{
> José Ripper Kós \\ Universidade Federal do Rio de Janeiro, Brasil \\ josekos@ufrj.br
}

\begin{abstract}
This article aims to promote the debate about the appliance of algorithmic thinking and parametric logic in the task of discussing, intervening and designing sustainable cities. More specifically, this paper will address the possibilities of developing generative systems in order to constitute digital models able to manage the various parameters that may be involved in functional, environmental and social proposition of cities. To that end, we assembled a theoretical referential about algorithmic and parametric framework, as well as new urbanism's concepts and principles such as Transit Oriented Development, Walkability and mix of uses.
\end{abstract}

Keywords: Urban Design; Algorithmic thinking; Parameterization; Sustainability

\section{Introdução}

O objetivo deste artigo é o de contribuir para um melhor entendimento sobre como o pensamento lógico pode ser aplicado no contexto complexo e interdisciplinar de projeto e planejamento urbano. Neste sentido, este trabalho procura promover o debate sobre a aplicação do pensamento algorítmico e da parametrização na tarefa de discutir, intervir e projetar cidades sustentáveis. De uma maneira mais específica, este paper pretende apresentar resultados obtidos em pesquisa de tese para doutoramento, que objetiva abordar o emprego de sistemas generativos de projeto na proposiçáo de cidades sustentáveis, de acordo com preceitos do Transit Oriented Development, walkability e uso misto (Farr, 2013; Leite, 2012; Dittmar \& Ohland, 2004)

A aplicação de modelos matemáticos como mecanismo para otimização do desenvolvimento urbano vem, há muito, sendo estudado e proposto por especialistas. Dantzig (1973 apud Leite, 2012) defende a utilização de modelos matemáticos para avaliar melhorias no desenvolvimento urbano por meio da otimizaçáo de infraestruturas em bairros de alta densidade. Salingaros (2010) demonstra possibilidades de gerar morfologias urbanas a partir da aplicação da legislação urbanística como código generativo. Paralelamente, Leite (2012), entende como cidade inteligente aquela em que as funçôes básicas da cidade - estabelecer trocas econômicas, sociais e culturais e gerar liberdade de vida e locomoção - são otimizadas por novas formas de tecnologia da informação e comunicação.

Mitchell e McCullough (1991) apresentam a revolução computacional como uma possível alternativa ao processo de projeto convencional, uma vez que o computador permite abordar maior complexidade de parâmetros e interaçóes. Esse incremento na capacidade intelectual do homem tem aberto novos horizontes criativos e materiais e o processo de concepçáo de projeto pode ser altamente mediado pela tecnologia digital. Ainda assim, é preciso ressaltar a posição do homem como central, pois dele vem a construção dos algoritmos, a alimentação dos parâmetros e definição das escolhas. Neste sentido é tão importante considerar o processo quanto ressaltar nele o projetista, ampliando seus operadores cognitivos, potencializando a apreensão e o processamento de fatores que devem ser considerados para novas formas de compreensão da cidade e do fenômeno urbano e, consequentemente, para o desenvolvimento de propostas que surjam deste entendimento.

Tanto Farr (2013) como Leite (1993) apontam que as cidades contemporâneas, estruturadas sob a lógica do transporte baseado no automóvel e nos grandes edifícios monofuncionais, em detrimento do transporte de massa e dos espaços públicos, devem ser repensadas e rediscutidas, e o aparato tecnológico deve estar a serviço da sociedade na busca por cidades sustentáveis. Se faz necessário pensar no desenvolvimento de cidades autossustentáveis através da integração entre planejamento urbano, urbanismo e arquitetura e neste contexto, torna-se extremamente recomendável, além de uma nova cultura das cidades, a existência de novas abordagens de projeto, que venham a complementar os atuais processos de pensamento das cidades.

Constituir uma abordagem algoritmo-paramétrica que contribua para o desenvolvimento de propostas de cidades sustentáveis 
pode transcender o entendimento do paradigma computacional como mero promotor de formas complexas, e, contribuir para processos capazes de constituir modelos que contemplem diversos parâmetros envolvidos na proposição funcional, ambiental e social das cidades e dos edifícios que elas contêm.

\section{Pensamento Algoritmico, Parametrização e Sistemas Generativos}

Terzidis (2006) define algoritmo como uma sequência finita de instruçóes para resoluçáo de um determinado problema, o que reforça o entendimento de que um algoritmo não representa, necessariamente, um programa ou software. Entretanto, combinar algoritmos com a capacidade de processamento do computador permite gerenciar grande quantidade de dados, números, cálculos e interaçôes, potencializando as possibilidades propositivas do arquiteto e criando novos cenários compositivos e propositivos.

Picon (2006 apud Terzidis, 2006, p.vii) permite entender as posturas frente as contribuiçóes digitais no processo de projeto em duas categorias. A primeira delas seria aquela que entende o computador apenas como uma ferramenta avançada que roda programas capazes de gerar formas sofisticadas, possibilitando maior domínio de concepçóes. Nesta lógica, entende-se que apesar do computador alterar significativamente a natureza do projeto, não é necessário ou até mesmo desejável o aprofundamento em detalhes de seus processos internos. A segunda categoria, representa o entendimento que considera inevitável o aprofundamento em questóes de programaçáo e dos processos internos dos algoritmos para conferir um uso verdadeiramente criativo ao computador. Desta forma, o pensamento é o de não limitar as soluçôes de projeto em experiências pré-definidas, mas sim explorar potenciais infinitos, soluçôes alternativas e possibilidades criativas livres de limitaçóes.

Woodbury (2010) identifica os sistemas convencionais de projeto como superados, pois se encontram estruturados em uma lógica de desenhar e apagar, fazer e desfazer. Neste sentido, a modelagem paramétrica se apresenta como introdutora de uma modificação fundamental, pois possibilita que as partes de um dado projeto se relacionem e modifiquem juntamente, de maneira coordenada. Construir algoritmos parametricamente significa relacionar dados, condições e variáveis, o que implica em pensar na relação entre as partes e nas decorrências e recomposiçóes destas relaçôes. Relacionar e recompor impóem modificaçóes fundamentais nos sistemas de projeto e na maneira que se empregam os mesmos.

Parametrizar significa definir os parâmetros necessários para uma especificaçáo completa ou relevante de um modelo ou objeto geométrico. Para Silva (2010), o desenho paramétrico é regulado pela declaraçáo dos parâmetros de um objeto particular, e não necessariamente de sua forma. Neste sentido, o foco de interesse náo é a forma, ou qualquer outro aspecto em si, mas os parâmetros que os determinam. Neste sentido, o desenho paramétrico apresenta uma abordagem essencialmente sistêmica, uma vez que permite considerar relaçóes entre os diversos elementos de um código, possibilitando constituir um verdadeiro complexo de elementos em interaçáo - um todo que se caracteriza através das inter-relaçóes entre as diversas partes constituintes. Henriques e Bueno (2010)
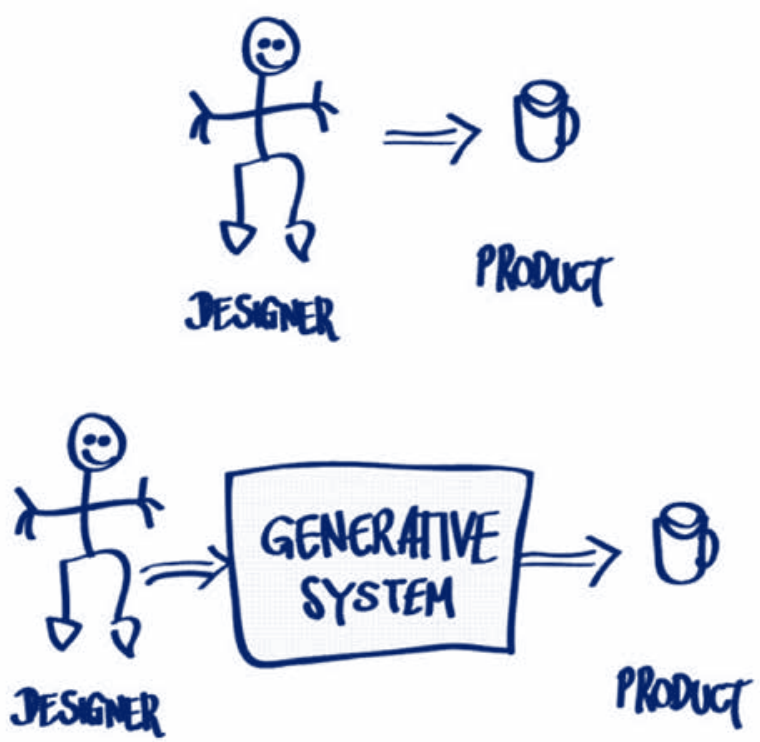

Figura 1: Diagrama de Fischer e Herr (2001 apud Celani, 2011) comparando o processo tradicional de projeto ao processo generativo.

entendem que o desenho paramétrico e o projeto algorítmico correspondem à codificação de um conjunto de regras ou relaçôes lógicas, geométricas e paramétricas, numa determinada sequência, para resolver um determinado problema.

\section{Sistemas Generativos}

Mitchell (1977) apresenta os sistemas generativos enquanto mecanismos para produzir uma variedade de soluçóes potenciais, orientadas para a resolução de um dado problema. Celani (2011), define sistema generativo como um método indireto de projeto, no qual o projetista não se preocupa apenas com a solução de um problema em particular em um contexto específico, mas também na construçáo dos parâmetros que compóem este sistema e em como as soluçóes serão obtidas. Nesta perspectiva, objetiva-se criar mecanismos mais ou menos genéricos, que possibilitem resolver problemas semelhantes em contextos diferentes.

Os sistemas generativos de projeto são aplicaçóes computacionais de criação que utilizam algoritmos, parametrização, simulação e técnicas de otimização de desempenho (KOLAREVIC, 2005). Esses aplicativos orientam a composição e organização a partir da avaliação das diferentes soluçôes, por meio de técnicas de simulação e da otimizaçáo progressiva das variáveis de performance, recorrendo a algoritmos orientados aos aspectos que se pretendem melhorar. Estabelece-se assim, uma ferramenta de projeto que além de ter as capacidades que se atribuem aos sistemas, inclui um feedback de desempenho na sua derivação organizacional, proporcionando, desse modo, objetivo e sentido que ultrapassam o campo estético. Esta nova abordagem de projeto inverte totalmente a tradicional ao propor ciclos iterativos de modelagem, simulação e avaliação.

Trabalhar neste paradigma significa estabelecer primeiramente os objetivos que determinado projeto se propóe a resolver. Em 
seguida, elabora-se um conjunto de regras e restriçóes que definem a funçáo que se deverá obedecer e o universo de possibilidades que o sistema generativo pode explorar. Finalmente, é introduzido um conjunto de soluçóes iniciais que serão progressivamente otimizadas, aproximando-se das metas de desempenho previamente estabelecidas.

\section{Transit Oriented Development}

Farr (2013) apresenta o Transit-Oriented Development (empreendimento urbano voltado para o transporte público) como um modelo de desenvolvimento urbano que que se enquadra no conceito do Novo Urbanismo, uma vez que proporciona mais opçôes de habitação e transporte, além de serviços variados que podem ser acessados a pé (priorização dos pedestres e vida urbana). Segundo Dittmar \& Ohland (2004), o Transit-Oriented Development (TOD) visa maximizar o acesso ao transporte coletivo e não-motorizado, por meio da implantação de estaçôes (de trem ou ônibus) centralmente localizadas e rodeadas por densidade relativamente alta.

OTransit-Oriented Development sintetiza o que Leite (2012) entende por um modelo de desenvolvimento urbano que promova altas densidades (maior que 250 habitantes por hectare) de modo qualificado, que misture funçôes urbanas (habitação, comércio e serviços) e que seja baseado em um eficiente sistema de mobilidade urbana que conecte núcleos adensados e estimule a caminhada (walkability) e o ciclismo. De acordo com Leite (2012, p.158) "Com isso, otimiza-se o uso das infraestruturas urbanas e promovese maior sustentabilidade - eficiência energética, melhor uso das águas e redução da poluição".

Para Farr (2013), o TOD é mais que simplesmente um projeto próximo a um estação de transporte público, mas sim, o conceito de um bairro em torno de uma estação, permeado por empreendimentos múltiplos, usos mistos, walkability e variedade de opçóes de transporte.

\section{Parâmetros e princípios parametrizáveis em Transit Oriented Development}

O pensamento algorítmico e a parametrização têm sido recorrentemente aplicados no campo do projeto arquitetônico, visando aperfeiçoar o design de edifícios e/ou seus componentes de similaridades paramétricas. Steinø \& Veirum (2005), entretanto, defendem que os componentes constituintes de um desenho urbano também compartilham similaridades que podem ser definidas parametricamente.

Aspectos fundamentais à implementação do Transit-Oriented Development como: densidade, uso e posicionamento de funçóes urbanas (aspectos que tipicamente se relacionam ao desenho urbano) podem ser definidos parametricamente. Sendo assim, é possível não apenas realizar um processo sistemático de desenho, mas também avaliar os pros e contras de cenários com diferentes ajustes para

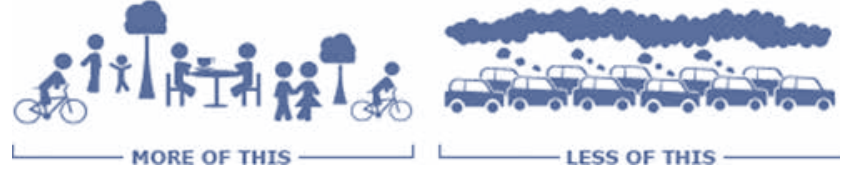

Figura 2: Conceito que sustenta a proposição do Transit Oriented Design. Fonte: http://www.walkscore.com. Acesso em 02/04/2014 cada parâmetro, de maneira a procurar soluçóes otimizadas para diferentes contextos.

\section{Walkable design}

Walkable design, ou projeto com princípios de walkability, considera os pedestres como a mais alta prioridade. Segundo Farr (2013), o conceito de walkability consiste na capacidade que um determinado bairro possui de conectar habitaçóes e pontos de comércio e serviço por meio de distâncias que podem ser percorridas a pé, conferindo assim, maior independência do automóvel e "uma rede viária em que se possa caminhar e um desenho que permita vida urbana e opçóes de transporte." (FARR, 2013, p.109).

Um instrumento que permite mensurar e, portanto, simular, programar ou reprogramar a walkability de um determinado bairro é o Walk Score, um algoritmo que, segundo Carr et al. (2011) gera uma pontuaçáo que se baseia na distância entre uma determinada unidade de habitação e os pontos de comércio e serviço mais próximos a ela. Estes pontos são classificados em 13 categorias (mercearias, cafés, restaurantes, bares, cinemas, escolas, parques, bibliotecas, livrarias, academias de ginástica, farmácias, lojas de ferragens, lojas de roupas/ música), são ponderados com mesmo peso e somados, resultando em um único índice que classifica a walkability de uma determinada localidade. Por exemplo, se em relação a uma determinada localidade o serviço mais próximo em uma categoria é de $0,4 \mathrm{~km}$ (5 minutos de caminhada), então o número máximo de pontos é atribuído para esta localidade nesta categoria. $\mathrm{O}$ número de pontos diminui à medida que a distância se aproxima de 1,6 km (30 minutos de caminhada) e não são atribuídos pontos para amenidades com mais de 1,6 km de distância. Cada categoria possui o mesmo peso e os pontos são somados e normalizados para produzir uma pontuação entre 0-100. O número de serviços disponíveis e a suas distâncias para as residências nas proximidades são os principais parâmetros para promover a walkability.

\section{Estação de transporte coletivo como centralidade}

Farr (2013), entende que concentrar pessoas que possam viver ou trabalhar próximas a uma parada de transporte, implica em

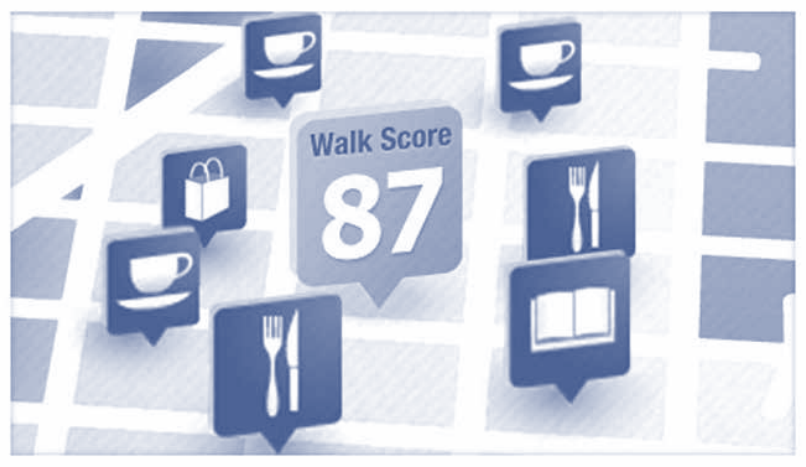

Figura $\exists$ : A distância entre funções urbanas e um determinado local, determina seu walkscore. $\mathrm{O}$ algoritmo que calcula esta pontuação, pode ser utilizado para alimentar um sistema generativo que permita propor vizinhanças com walkability otimizada. Fonte: http:// www.walkscore.com. Acesso em 13/02/2014 
criar um mercado estável de pessoas que percorram uma distância curta a pé até o serviço de transporte público. Ainda segundo Farr (2013, p.103) "A quantificação dessa relação entre a densidade populacional em um corredor de transporte público e a sua capacidade de sustentar o transporte é essencial para o urbanismo sustentável”. Leite (2012) confirma a importância da estação de transporte como ponto estruturador dos bairros ou unidades de vizinhança, como um nó regional, que contenha usos mistos nas proximidades e densidade qualificada, incluindo escritórios, áreas residenciais, varejo e que, em volta da mesma se articulem densidades decrescentes dentro de um diâmetro de 10 minutos de caminhada. Além disso, é fundamental a presença de sistemas de transporte de apoio, incluindo carros, bondes, incluindo o uso fácil de bicicletas, scooters e afins. Como parâmetros norteadores deste princípio que podem ser incorporados a um sistema generativo, tem-se: (a) a densidade residencial mínima necessária para sustentar diferentes modais, conforme relacionado por Pushkarev \&Zupan (1977); (b) a posição da estação de transporte em relação ao bairro e suas distâncias para as residências e locais de trabalho e (c) densidade qualificada e decrescente proporcionalmente à distância da estação de transporte.

Tabela 1: Modais de transporte público relacionados com a densidade residencial. Fonte: Pushkarev \& Zupan (1977).

\begin{tabular}{|c|c|c|}
\hline Modal & Serviço & $\begin{array}{l}\text { Densidade } \\
\text { residencial minima }\end{array}$ \\
\hline Ônibus local & $\begin{array}{l}\text { "Mínimo": paradas a } \\
\text { cada } 800 \mathrm{~m}, 20 \text { ônibus } \\
\text { por dia }\end{array}$ & 10,0 \\
\hline Ônibus local & $\begin{array}{l}\text { "Intermediário": paradas } \\
\text { a cada } 800 \mathrm{~m}, 40 \text { ônibus } \\
\text { por dia }\end{array}$ & 17,5 \\
\hline Ônibus local & $\begin{array}{l}\text { "Frequente": paradas a } \\
\text { cada } 800 \mathrm{~m}, 120 \text { ônibus } \\
\text { por dia }\end{array}$ & 37,5 \\
\hline $\begin{array}{l}\text { Ônibus Expresso } \\
\text { (Acessado à pé) }\end{array}$ & $\begin{array}{l}\text { Cinco ônibus durante } \\
\text { um período de pico de } \\
\text { duas horas }\end{array}$ & $\begin{array}{l}37,5 \\
\text { Densidade padrão em } \\
\text { cobertura de } 5 \mathrm{~km}^{2}\end{array}$ \\
\hline $\begin{array}{l}\text { Ônibus Expresso } \\
\text { (Acessado por } \\
\text { automóvel) }\end{array}$ & $\begin{array}{l}\text { De cinco a dez ônibus } \\
\text { durante um período de } \\
\text { duas horas }\end{array}$ & $\begin{array}{l}7,5 \\
\text { Densidade padrão em } \\
\text { cobertura de } 50 \mathrm{~km}^{2}\end{array}$ \\
\hline Metrô leve & $\begin{array}{l}\text { Partidas a cada cinco } \\
\text { minutos ou menos } \\
\text { durante horário de pico }\end{array}$ & $\begin{array}{l}22,5 \\
\text { Densidade padrão para } \\
\text { um corredor de } 65 \mathrm{a} \\
260 \mathrm{Km}^{2}\end{array}$ \\
\hline Ônibus em corredor & $\begin{array}{l}\text { Partidas a cada cinco } \\
\text { minutos ou menos } \\
\text { durante horário de pico }\end{array}$ & $\begin{array}{l}30 \\
\text { Densidade padrão para } \\
\text { um corredor de } 260 \mathrm{a} \\
390 \mathrm{Km}^{2}\end{array}$ \\
\hline Trem suburbano & 20 trens por dia & 2,5 a 5,0 \\
\hline
\end{tabular}

\section{Considerações Finais}

Contemplar a lógica paramétrica e introduzir o pensamento algorítmico na prática do projeto urbano pode significar incorporar à discussão sobre a cidade contemporânea, uma nova abordagem que pode contemplar uma grande variedade de parâmetros e suas

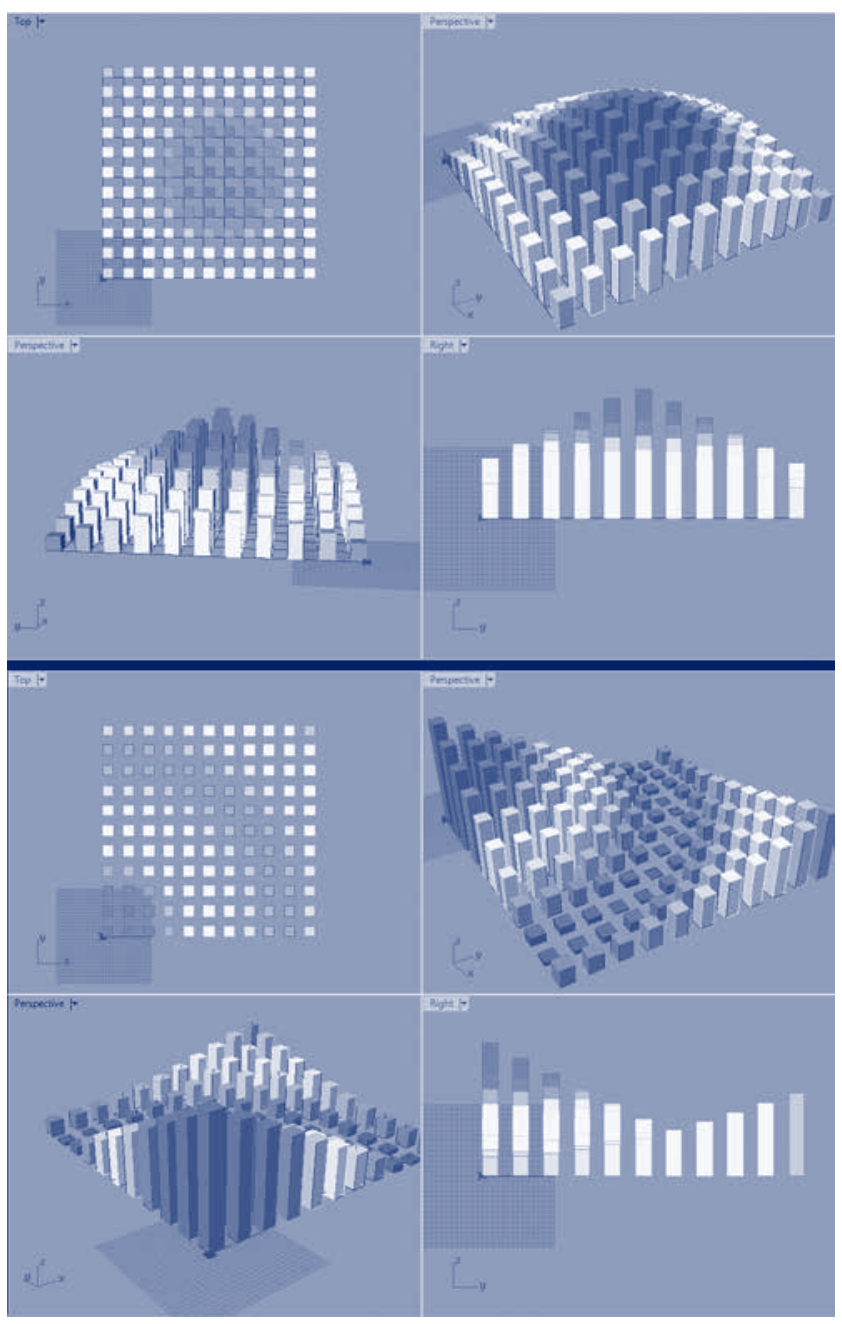

Figura 4: Estudos iniciais com sistemas generativos que propóem estruturações urbanas com gabaritos e densidades variáveis de acordo com a proximidade em relação a um ponto ou eixo de interesse.

inter-relaçôes. Direcionar este raciocínio para uma contribuição que transcenda questóes meramente formais e busque sistematizar uma lógica projetual baseada na questão da sustentabilidade em seus diversos fatores pode ser um ponto de partida para a proposição de configuraçóes urbanas mais eficientes, uma alternativa à complexidade da problemática urbana atual.

A construçáo e utilização de sistemas generativos estruturados com base em parâmetros provenientes do Transit Oriented Development, permite produzir uma variedade de soluçóes potenciais para o posicionamento de diferentes funçóes urbanas, bem como para a regulação de densidades qualificadas e decrescentes conforme a distância para a estação de transporte. Considerar este conjunto de soluçóes potenciais permite ampliar as possibilidades de análise, discussão e intervenção, contribuindo para intervençóes em áreas consolidadas ou auxiliando na concepção de novos bairros, corredores e centros urbanos alinhavados com os preceitos do urbanismo sustentável. 
Como desdobramentos da pesquisa aqui apresentada, está o desenvolvimento e avaliação de sistemas generativos que sejam empregados na estruturação de projetos urbanos que utilizem otimização para o posicionamento de diversas funções urbanas, bem como para a regulação de diferentes densidades em função de suas distâncias para a estação de transporte e demais aspectos envolvidos no Transit Oriented Development.

\section{Agradecimentos}

Agradecemos ao Programa de Pós-Graduaçáo em Urbanismo (PROURB) da Universidade Federal do Rio de Janeiro (UFRJ), bem como a Faculdade de Engenharia da Universidade Federal de Juiz de Fora (UFJF), por viabilizarem, financeiramente, a apresentação deste artigo neste congresso.

\section{Referências}

Carr, L. B., Dunsigen, I. D., \& Marcus, B. H. (2011) Validation of walk score for estimating access to walkable amenities. British journal sports medicine, v.45, p. 1144-1158.

Celani, G. (2011). Algorithmic Sustainable Design. Uma visão crítica do projeto generativo. Resenhas Online, ano 10, n. 116.03. http://www.vitruvius.com.br/revistas/read/drops/10.030/2109

Dittmar, H., \& Ohland, G. (2004). The new transit town: Best practices in Transit-Oriented Development. Washington: Island Press.
Farr, D. (2013). Urbanismo sustentável: Desenho urbano com a natureza. Porto Alegre: Bookman.

Henriques, G. C., \& Bueno, E. (2010). Geometrias complexas e desenho paramétrico. DROPS, ano 10, n. 030.08. http://www. vitruvius.com.br/revistas/read/drops/10.030/2109

Leite, C. (2012). Cidades sustentáveis cidades inteligentes: Desenvolvimento sustentável num planeta urbano. Porto Alegre: Bookman.

Kolarevic, B. (2005). Architecture in the digital age: design and manufacturing. Londres: Taylor \& Francis.

Mitchell, W. J. (1977). Computer-aided architectural design. Nova York: Van Nostrand Reinhold.

Mitchell, W. J., \& McCullough, M. (1991). Digital design media. Nova York: Van Nostrand Reinhold.

Pushkarev, B., \& Zupan, J. M. (1977). Public transportation and land use policy. Nova York: Indiana University Press.

Salingaros, N. (2010). Twelve lectures on architecture: Algorithmic sustainable design. Solingen: Umbau-Verlag.

Silva, R. C. (2010). Urbanismo paramétrico: Parametrizando urbanidade. Recife: UFPE.

Steinø, N., \& VEIRUM, N. (2005) Parametric Urban Design. CONGRESS AESOP 5, Viena, Anais do Congresso

Terzidis, K. (2006). Algorithmic architecture. Nova York: Routledge. Woodbury, R. (2010). Elements of parametric design. Nova York: Routledge. 